\title{
In-vivo evaluation of the response of Galleria mellonella larvae to novel copper(II) phenanthroline-phenazine complexes
}

\author{
Garret Rochford ${ }^{\mathrm{a}, *}$, Zara Molphy ${ }^{\mathrm{b}}$, Niall Browne ${ }^{\mathrm{c}}$, Carla Surlis ${ }^{\mathrm{c}}$, Michael Devereux ${ }^{\mathrm{a}}$, \\ Malachy McCann ${ }^{\mathrm{d}}$, Andrew Kellett ${ }^{\mathrm{b}}$, Orla Howe ${ }^{\mathrm{a}}$, andKevin Kavanagh ${ }^{\mathrm{c}}$ \\ a Centre for Biomimetics and Therapeutics and Focas Research Institute, Dublin Institute of Technology, Camden Row, Dublin 8, Ireland \\ ${ }^{\mathrm{b}}$ School of Chemical Sciences and National Institute for Cellular Biotechnology, Dublin City University, Dublin 9, Ireland \\ ${ }^{\mathrm{c}}$ Department of Biology, Maynooth University, Maynooth, Co. Kildare, Ireland \\ d Department of Chemistry, Maynooth University, Maynooth, Co. Kildare, Ireland
}

\section{A R T I C L E I N F O}

\section{Keywords:}

Chemical nuclease

Copper phenanthrene

Galleria mellonella

in-vivo toxicity

DNA

LFQ proteomics

\begin{abstract}
A B S T R A C T
Herein we report the in-vivo characterisation and metabolic changes in Galleria mellonella larvae to a series of bischelate copper(II) phenanthroline-phenazine cationic complexes of $\left[\mathrm{Cu}(\mathrm{phen})_{2}\right]^{2+}(\mathrm{Cu}-\mathrm{Phen}),[\mathrm{Cu}(\mathrm{DPQ})$ $(\mathrm{Phen})]^{2+}$ (Cu-DPQ-Phen) and [Cu(DPPZ)(Phen) $]^{2+}$ (Cu-DPPZ-Phen) (where phen = 1,10-phenanthroline,

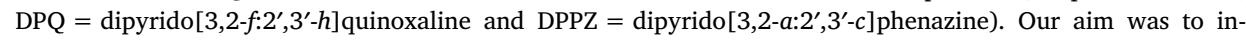
vestigate the influence of the systematic extension of the ligated phenazine ligand in the G. mellonella model as a first step towards assessing the in-vivo tolerance and mode of action of the complex series with respect to the well-studied oxidative chemical nuclease, $\mathrm{Cu}$-Phen. The Lethal Dose ${ }_{50}\left(\mathrm{LD}_{50}\right)$ values were established over dose ranges of $2-30 \mu \mathrm{g}$ at 4-, 24-, 48- and $72 \mathrm{~h}$ by mortality assessment, with Cu-Phen eliciting the highest mortality at $4 \mathrm{~h}$ (Cu-Phen, $12.62 \mu \mathrm{g}<\mathrm{Cu}-\mathrm{DPQ}-\mathrm{Phen}, 21.53 \mu \mathrm{g}<\mathrm{Cu}$-DPPZ-Phen, 26.07 $\mu \mathrm{g}$ ). At other timepoints, a similar profile was observed as the phenazine $\pi$-backbone within the complex scaffold was extended. Assessment of both cellular response and related gene expression demonstrated that the complexes did not initiate an immune response. However, Label-Free Quantification proteomic data indicated the larval response was associated with upregulation of key proteins such as Glutathione $S$-transferase, purine synthesis and glycolysis/gluconeogenesis (e.g. fructose-bisphosphate aldolase and glyceraldehyde-3-phosphate). Both Cu-Phen and Cu-DPQ-Phen elicited a similar in-vivo response in contrast to Cu-DPPZ-Phen, which displayed a substantial increase in nitrogen detoxification proteins and proteins with calcium binding sites. Overall, the response of G. mellonella larvae exposure to the complex series is dominated by detoxification and metabolic proteome response mechanisms.
\end{abstract}

\section{Introduction}

Almost 40 years since receiving Federal Drug Administration (FDA) approval, cisplatin still remains one of the most important chemotherapies available today for the combination treatment of cancers including metastatic testicular and ovarian cancers, bladder and lung. However, dose limiting side effects including neurotoxicity and nephrotoxicity and the development of both acquired and inherently resistant cancers continue to be an ongoing issue in its treatment success. As such, recent research activity has focused on the rational design of metallo-agents including ruthenium [1-5], iron [6, 7], gold [8-10] and copper [11-19] with alternative mode of action to the mono-nuclear cis- $\left[\mathrm{PtX}_{2}(\mathrm{amine})_{2}\right]$ chemotype $(\mathrm{X}=$ leaving group, amine $=$ neutral or carrier group) shared by cisplatin and its derivatives [20].
Copper is an endogenous metal ion that plays an essential role in the structure and activity of multiple functional protein classes, such as enzymes designated to detoxification and oxidative phosphorylation. The essential nature of copper in the cell and its complex homeostasis through specific transporters and trafficking proteins; Copper Transporter 1/2 (CRT1 and CRT2), ATPase copper transporting 7 alpha/beta (ATP7 $\alpha$ and ATP7 $\beta$ ) holds a strong potential for the utilisation of copper as part of a metallodrug [21].

The therapeutic development of copper complexes has progressed to an advanced stage with two members of the Reactive Oxygen Species (ROS)-active, mixed chelate Casiopeinas ${ }^{\circledR}$ class recently entering phase I clinical trials [22]. The compounds have previously shown antiproliferative and antitumoural effects in medulloblastoma [23], glioma [24] and colorectal adenocarcinoma [25] cell lines. Their mechanism of

\footnotetext{
* Corresponding author.

E-mail address: garret2400@gmail.com (G. Rochford).
} 


\author{
Abbreviations \\ 2D PAGE 2 dimensional poly acrylamide gel electrophoresis \\ AICAR transformylase-phosphoribosylaminoimidazolecarbox- \\ amide formyltransferase \\ ATP7A/B ATPase copper transporting alpha/beta \\ CTR1/2 Copper Transporter 1/2 \\ DMSO Dimethyl Sulfoxide \\ DNA Deoxyribonucleic Acid \\ DTT Dithiothreitol \\ FDA Federal Drug Administration \\ FDR false discovery rate \\ GO Gene Ontology \\ GST Glutathione $S$-transferase \\ HSP Heat Shock Protein \\ IAA Iodoacetamide \\ IMPI Inducible of Metalloproteinase Inhibitor
}

\begin{tabular}{|c|c|}
\hline KEGG & Kyoto Encyclopedia of Genes and Genomes \\
\hline $\mathrm{LD}_{50}$ & Lethal Dose $(50 \%)$ \\
\hline LFQ & Label Free Quantitative (proteomics) \\
\hline MDR & Multi Drug Resistance \\
\hline mRNA & messenger Ribonucleic Acid \\
\hline NAD & Nicotinamide Adenine Dinucleotide \\
\hline NCI DTP & $\begin{array}{l}\text { National Cancer Institute Developmental Therapeutics } \\
\text { Program }\end{array}$ \\
\hline PCA & principle component analysis \\
\hline qRT-PCR & quantitative Real-Time Polymerase Chain Reaction \\
\hline ROS & Reactive Oxygen Species \\
\hline \multicolumn{2}{|c|}{$\begin{array}{l}\text { SAICAR synthase pho- } \\
\text { ocarboxamide synthase }\end{array}$} \\
\hline SBC3 & $\begin{array}{l}\text { 1,3-dibenzyl-4,5-diphenyl-imidazol-2-ylidene } \\
\text { acetate }\end{array}$ \\
\hline SOD & Superoxide Dismutase \\
\hline TCA & Tricarboxylic Acid (cycle) \\
\hline
\end{tabular}

action is not fully understood, however they are believed to exert their biological effects through (i) binding Deoxyribonucleic Acid (DNA) with intercalative and non-intercalative methods at high affinities, (ii) degrading nucleic acids through the generation of ROS and depleting the antioxidant systems, and (iii) inducing mitochondrial toxicity [26]. Further examples of ternary mixed ligand chelated copper (II) complexes include a developmental therapeutic $[\mathrm{Cu}(o$-phthalate $)(1,10-$ phenanthroline) $]^{2+}$ encorporating a bis-chelate dicarboxylate and $N, N^{\prime}$-intercalative square planar coordination scaffold that has recently shown endogenous ROS production inducing DNA damage and mitochondrial depolarisation resulting in apoptotic induction [16]. Furthermore, the cytotoxic profile of the complex within the National Cancer Institute (NCI) Developmental Therapeutics Program (DTP) 60 human cancer cell panel revealed a novel mode of action to existing metal-based therapeutics.

At the heart of the promising chemotherapeutic potential exerted by many copper(II) complexes lies the artificial metallo-nuclease activity of the parent copper(II) bis-1,10-phenanthroline (Cu-Phen) agent [27]. Evidence suggests the complex binds DNA predominately in the minor groove and in its reduced form abstracts a hydrogen atom primarily from the $\mathrm{C}^{\prime}$ ' deoxyribose position resulting in strand damage [28, 29], with di-copper chemotypes demonstrating singlet oxygen and superoxide production [30]. However, the nuclease binds both nucleic acids and proteins without specificity inducing general toxicity, and is thus considered a "promiscuous" agent [31]. Accordingly, manipulation of this chemotype represents an interesting developmental challenge. With this in mind, a range of novel $\mathrm{Cu}(\mathrm{II})$ chemical nucleases of [Cu (phen) $\left.\left(N, N^{\prime}\right)\right]^{2+}$ carrying designer phenazine type-intercalators (where $N, N^{\prime}$ represents phen $=1,10$-phenanthroline, $\mathrm{DPQ}=$ dipyrido[3,2$\left.f: 2^{\prime}, 3^{\prime}-h\right]$ quinoxaline and $\mathrm{DPPZ}=$ dipyrido $\left[3,2-a: 2^{\prime}, 3^{\prime}-c\right]$ phenazine) were developed by Molphy et al. to identify how the systematic extension of the ligated phenanthrene ligand influences nucleotide binding affinity, base selectivity, oxidative chemical nuclease activity, and cytotoxicity within human cancer cells [32]. Agents within this series showed potent intercalative selectivity, high-affinity duplex-DNA binding constants and significant in-vitro cytotoxicity in the SKOV3 cisplatin-resistant ovarian cell line.

Galleria mellonella larvae have become an important model for studying human pathogens in addition to being an evaluative mechanism for antimicrobial and antifungal testing [33-36]. A number of factors contribute to this Lepidoptera species being a viable screening model such as: the possession of a similar humoral and cellular immune response to mammals [35, 37], the ability to incubate pathogens at human physiological temperature [34], the physical size of the larvae allowing for ease of inoculation and visual effects being readily observable [38], and having lower ethical and financial restrictions associated with their use [39]. Haemocyte-mediated ROS production has been proposed to be central to the immune response of $G$. mellonella [40]. Several genes have been found to be up regulated during infection and provide a good indicator of the immunogenic nature of the insult on the larvae [41]. Several studies examining toxicities and assessing larval tolerance have been undertaken against a range of metal complexes. The cytotoxicity and subsequent biological activity of $\mathrm{Cu}(\mathrm{II}) 1$, 10-phenanthroline and $\mathrm{Cu}(\mathrm{II})$ 1, 10-phenanthroline-5,6-dione was well tolerated by the larvae in addition to showing strong in-vitro activity in mammalian cells lines [42]. A further study involving a series of Imidazole Schiff base ligands complexed to $\mathrm{Ag}(\mathrm{I}), \mathrm{Cu}(\mathrm{II})$ and $\mathrm{Zn}$ (II) were shown to be well tolerated in G. mellonella larvae [43]. A subsequent study showed the tolerance of larvae to $\mathrm{Ag}(\mathrm{I})$ carbine complex provided an opportunity to assess the antimicrobial activity which showed increased survival following infection with Candida albicans [44]. G. mellonella larvae have also demonstrated a high degree of tolerance to both $\mathrm{Cu}^{2+} 1,10$-phenanthroline octanedionate and $\mathrm{Mn}^{2+} 1,10$-phenanthroline octanedionate complexes [45]. A mechanistic study of this nature would help provide key insights into the activity and potential molecular targets of $\mathrm{Cu}(\mathrm{II})$ phenanthroline-phenazine complexes in an in-vivo context and aid in future biological testing.

Given the promising activity of $\mathrm{Cu}(\mathrm{II})$ phenanthroline-phenazine complexes, [32, 46] the current study seeks to characterise the in-vivo toxicity, immune related gene expression and proteomic effects of $\mathrm{Cu}$ Phen, Cu-DPQ-Phen and Cu-DPPZ-Phen in G. mellonella larvae. Proteomic responses were recorded through Label Free Quantification (LFQ) in addition to 2-Dimensional Polyacrylamide gel electrophoresis (2D PAGE) methods. LFQ allows a high-resolution assessment of the proteomic changes in the larvae and is becoming an increasingly important tool in identifying the mode of action in in-vitro mammalian cell models [47, 48]. Owing to the similarity between the larval and mammal system, this approach will provide valuable insights into the potential mode of action of the phenazine-functionalised $\mathrm{Cu}$ (II) phenanthroline complexes in mammalian models.

\section{Materials and methods}

\subsection{Preparation of $\mathrm{Cu}(\mathrm{II})$ complexes}

Cu-Phen (1), Cu-DPQ-Phen (2) and Cu-DPPZ-Phen (3) (Fig. 1) were synthesised and characterised as previously described [32]. Complexes were initially dissolved in Dimethyl Sulfoxide (DMSO) (Sigma, Ireland) followed by dilution in working aqueous solution. Individual doses were made up in sterile water from the stock solution producing a range between 1500 and $200 \mu \mathrm{g} \mathrm{cm}^{-3}$. 


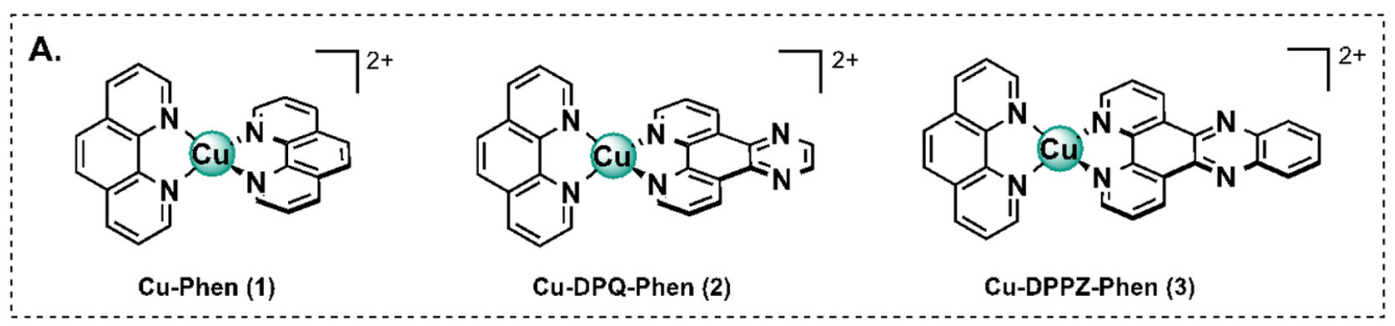

Fig. 1. Molecular structure of $\mathrm{Cu}(\mathrm{II})$ coordination complexes (1-3).

\subsection{Galleria mellonella mortality and haemocyte density assessment}

Galleria mellonella larvae of the 6th instar development stage were sourced from Livefoods Direct Ltd. (Sheffield, England) and were stored in the dark at $15{ }^{\circ} \mathrm{C}$ in wood shavings prior to testing. Thirty three larvae for each replicate $(11 \times 3)$ (average weight $0.3 \pm 0.05 \mathrm{~g}$ ) with no cuticle decolouration were used for each experimental condition. All test solutions were prepared immediately prior to testing. Larvae were inoculated with $20 \mu \mathrm{L}$ of the test complex [49]. A solvent control (8.94\% DMSO) in Sterile MilliQ water was inoculated along with shaminoculations and undisturbed controls. Larval mortality was recorded over $72 \mathrm{~h}$ after incubation at $30^{\circ} \mathrm{C}$. The lethal dose (LD) concentration inducing $50 \%$ larval death $\left(\mathrm{LD}_{50}\right)$ for each timepoint was calculated using non-linear regression analysis (GraphPad Prism ver. 5.0). Haemocyte density assessment was determined [50] after inoculation with the $24 \mathrm{~h} \mathrm{LD}_{50}$ exposures. The exposure was performed on 4 independent occasions, utilising 5 larvae per exposure. Haemocyte density was represented by mean \pm standard deviation.

\subsection{Induction of IMPI and transferrin by quantitative Real Time - PCR ( $q R T-P C R)$}

Inducible metalloproteinase inhibitor (IMPI) and transferrin are commonly seen to be raised in insect based immune reactions [51, 52]. IMPI and transferrin (Table 1) were therefore assessed for their expression relative to the reference gene S7e (ribosomal subunit) after larvae were inoculated with the $24 \mathrm{~h} \mathrm{LD}_{50}$ value of Cu-Phen (1), Cu-DPQ-Phen (2) and CuDPPZ-Phen (3). Controls for the solvent, injection (sham-inoculation) and temperature (undisturbed) were included in the assessment. Total RNA was extracted from the larvae by snap freezing (liquid nitrogen) 3 larvae (representative of each condition) as previously described [53]. qRT-PCR was performed on the 7500 Real-Time PCR system (Applied Biosystems ${ }^{\circledR}$ ) using SYBR FAST qPCR kit (KAPA Biosciences) (See S-1 for parameters).

\subsection{Label free quantification (LFQ) - proteomics}

Larvae were inoculated with the $24 \mathrm{~h} \mathrm{LD}_{50}$ values of Cu-Phen (1) (8.94 $\mu \mathrm{g})$, Cu-DPQ-Phen (2) $(11.47 \mu \mathrm{g})$, Cu-DPPZ-Phen (3) $(25.05 \mu \mathrm{g})$ and solvent control (8.94\% DMSO in MilliQ grade water). Haemolymph protein from 5 pooled (performed 4 independent times) larvae were extracted and quantified using the Bradford method [55]. Samples were normalized to $100 \mu \mathrm{g}$ prior to reduction with dithiotreitol (DTT; $200 \mathrm{mM}$ ), followed by alkylation with iodoacetamide (IAA; $1 \mathrm{M}$ ) and digested with sequence grade trypsin (Promega, Ireland) at a ratio of 1:40 trypsin to protein over night at $37^{\circ} \mathrm{C}$. Prior to C18 column cleanup, samples were separated by 1 Dimensional (1D) gel electrophoresis along with a size ladder and stained with coomassie blue to verify the presence and quantity of proteins in the samples. Following verification, samples were subjected to a clean-up procedure utilising C18 columns with spin filters (Medical Supply Company, Ireland). Peptide mix was separated on a Dionex Ultimate 3000 (RSLC nano) chromatography system with increasing gradient of acetonitrile on a Biobasic C18 PicofritTM column (100 mm length, $75 \mathrm{~mm}$ ID), using a $60 \mathrm{~min}$ reverse phase gradient at a flow rate of $250 \mathrm{~nL} \mathrm{~min}^{-1}$. High-resolution Mass Spectrometry (MS) (300-2000 Da) was performed using the Q Exactive (ThermoFisher, USA) to select the 15 most intense ions prior to MS/MS Q. Protein spots identified in the 2-Dimensional Polyacrylamide Gel Electrophoresis (2D PAGE) analysis (see S-1 for details) were excised and trypsin digested similarly to the method described. [56]

Proteins were identified through the Andromeda search engine [57] in MaxQuant (ver. 1.2.2.5, http://maxquant.org/) to correlate the data against a 6-frame translation of the expressed sequence tag contigs identified from complementary DNA (cDNA) for G. mellonella [58]. First search peptide tolerance of $20 \mathrm{ppm}$ was followed by the second search peptide tolerance of $4.5 \mathrm{ppm}$ with cysteine carbamidomethylation as a fixed modification, $\mathrm{N}$-acetylation of protein and oxidation of methionine as variable modification, and a maximum of 2 missed cleavage sites allowed. False discovery rate (FDR) was set to $1 \%$ for both peptides and proteins and FDR was estimated following searches against a target decoy database. Peptides with a minimum length of seven amino acids were considered for identification and proteins were only considered identified when more than one unique peptide for each protein was observed.

\subsection{Statistical analysis}

Larval mortality was used to establish $\mathrm{LD}_{50}$ using non-linear regression analysis (GraphPad Prism, ver. 5.0). Gene expression was assessed through the use of relative expression to the reference gene S7e and was technically replicated on four occasions. Analysis of critical threshold values was performed as per Livak and Schmittgen relative expression method [59]. LFQ proteomics was run on 4 separate occasions with Sodium Dodecyl Sulfate Polyacrylamide Gel Electrophoresis (SDS PAGE) used to check the integrity of samples prior to Liquid Chromatography/Mass Spectrometry (LC/MS) injection. Statistical and graphical analysis of the LFQ proteomics was performed using Perseus

Table 1

Sequence of primers for IMPI and transferrin.

\begin{tabular}{lllll}
\hline Gene (primers) & Oligonucleotides sequence $\left(5^{\prime}-3^{\prime}\right)$ & Fragment size (base pair (bp)) & Reference & Function (encodes) \\
\hline S7e F & ATGTGCCAATGCCCAGTTG & 131 & {$[54]$} & Structural ribosomal protein \\
$\quad$ S7e R & GTGGCTAGGCTTGGGAAGAAT & & & Iron transport and binding \\
Transferrin F & CCCGAAGATGAACGATCAC & 535 & {$[41]$} & Inhibits pathogen secreted enzymes \\
$\quad$ Transferrin R & $\begin{array}{l}\text { CGAAAGGCCTAGAACGTTTG } \\
\text { IMPI F }\end{array} \quad$ ATTTGTAACGGTGGACACGA & 409 & {$[41]$} &
\end{tabular}


v. 1.5.0.31. $\log 2$-transformation was performed on all LFQ intensities that met the identification criteria with subsequent ANOVA of significance and $t$-tests between the solvent control and the test complexes exposures. The $p$-value of 0.05 was set with significance determined using FDR correction (Benjamini-Hochberg). Proteins were only included when they were present in at least 3 of 4 biological replicates. Proteins which had LFQ intensity values of zero (indicating absence or low abundance) were included in the study only when the protein was absent in one group and present in at least three replicates of another group. Imputation was used to correct for missing identifications in samples based on Gaussian distribution using the lowest value for each dataset, which was calculated as being 1.75 downshift from the mean value and 0.25 width in the downshift for the standard deviation. The Blast2GO suite (www.blast2GO.com) of software tools was used to assign annotation, enzyme code, Kyoto Encyclopedia of Genes and Genomes (KEGG) and Gene Ontology (GO) mapping. GO mapping for biological processes and molecular functions was graphed at level 4 ontology.

\section{Results}

\subsection{Larval mortality assay and haemocyte count}

G. mellonella larvae were administered with Cu-Phen (1), Cu-DPQPhen (2), Cu-DPPZ-Phen (3) and cisplatin with the level of toxicity being assessed by the mean mortality (\%) over $72 \mathrm{~h}$ (Supplementary Table I and II). No mortality (data not shown) was recorded at any timepoint after incubation of solvent (8.94\% DMSO in MilliQ water), sham inoculated and undisturbed controls. The results of the individual larval responses to the inoculated doses and timepoints are detailed in $\mathrm{S}-1$. The $\mathrm{LD}_{50}$ values (Table 2) from Cu-Phen (1), Cu-DPQ-Phen (2) and Cu-DPPZ-Phen (3) decrease over the increasing timepoints with $\mathrm{Cu}-$ Phen (1) showing superior toxicity to both Cu-DPQ-Phen (2) and CuDPPZ-Phen (3) at all timepoints. Haemocytes were numerated from the haemolymph extracted from 5 larvae per treatment $\left(\mathrm{LD}_{50}\right.$ value at $24 \mathrm{~h}$ ) with this procedure replicated 4 times (for statistical validity). No significant changes (data not shown) were observed between any of the controls and test complex exposures.

\subsection{Induction of IMPI and transferrin assessed by $q R T-P C R$}

Larvae were exposed to the $24 \mathrm{~h} \mathrm{LD}_{50}$ value of $\mathrm{Cu}-\mathrm{Phen}(1), \mathrm{Cu}-$ DPQ-Phen (2) and Cu-DPPZ-Phen (3). Solvent control, sham-inoculation and undisturbed control were utilised as previously described. Both transferrin and IMPI were normalized against the expression of S7e reference gene and all larval treatments were compared to the solvent control. Both sham-inoculation and undisturbed controls produced similar expression levels (data not shown). Fig. 2 demonstrates the expression of both genes. A significant decrease in IMPI expression (Fig. 2) was observed in Cu-Phen (1), Cu-DPQ-Phen (2) and Cu-DPPZPhen (3) treated larvae in comparison to the solvent control. In all $\mathrm{LD}_{50}$ complex exposures a significant decrease in transferrin activity (Fig. 2) was observed with respect to the solvent control. The solvent control demonstrated decreased expression in both measured genes in relation to the undisturbed biological control.

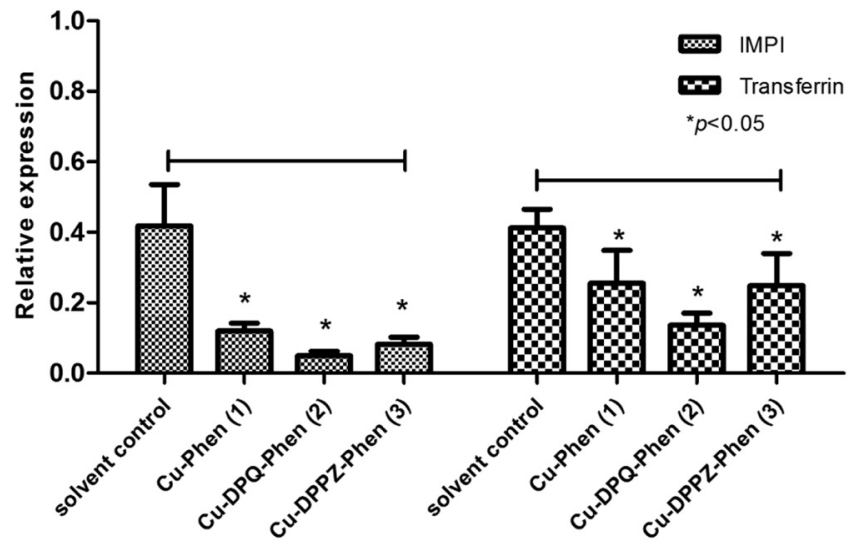

Fig. 2. Relative expression of IMPI and transferrin after $24 \mathrm{~h}$ exposure to $\mathrm{LD}_{50}$ value of Cu-Phen (1), Cu-DPQ-Phen (2) and Cu-DPPZ-Phen (3). Gene expression is displayed relative to the undisturbed control with the solvent control used to determine significance $(p<0.05)$.

\subsection{Label free quantification (LFQ) - Proteomics between test exposures and control}

The haemolymph of larvae was extracted after the $24 \mathrm{~h}$ exposure to the $\mathrm{LD}_{50}$ value of the complex series in order to assess the difference in protein abundance between the treated and control larvae. A total of 299 proteins were detected with 2 or more peptides. One hundred and four proteins were found to be significantly altered in abundance or uniquely detected across the 4 conditions (Table 3 ). Nine proteins were found to be absent or below the limit of detection following exposure to Cu-DPQ-Phen (2). Twelve proteins were found to be absent or below the detection limit following exposure to $\mathrm{Cu}$-Phen (1). Four proteins were found to be absent or below the limit of detection after exposure to Cu-DPQ-Phen (2) and Cu-DPPZ-Phen (3). One protein was found to be absent or below the limit of detection after exposure to Cu-Phen (1) and Cu-DPPZ-Phen (3). Twenty-three proteins were found to be absent or below the limit of detection after exposure to $\mathrm{Cu}-\mathrm{Phen}(\mathbf{1})$ and $\mathrm{Cu}$ DPQ-Phen (2). Table 3 demonstrates increasing numbers of significantly up regulated proteins in the following pattern: Cu-Phen (1) < Cu-DPQ-Phen (2) < Cu-DPPZ-Phen (3). In the case of Cu-DPPZPhen (3) exposure, a greater number of antimicrobial proteins were observed to be significantly down regulated while a greater number of metabolic proteins and proteins containing calcium binding sites were up regulated. Principle component analysis (PCA) (Fig. 3) was used to visualise the variation in protein abundance across the individual replicates. The proteomes of larvae exposed to the solvent control and CuDPPZ-Phen (3) showed clustering that was widely separated by component 1 (greatest measure of profile divergence), however Cu-Phen (1) and Cu-DPQ-Phen (2) were closely clustered, indicating a similar protein expression profile. Hierarchical clustering (Supplementary Fig. 2) similarly reflected the PCA. Four replicates were included for the solvent control and one replicate was removed from each of the test exposures due to lack of clustering with the parent group. GO terms were categorised by both biological processes (Fig. 4(A)) and molecular

Table 2

Calculated $\mathrm{LD}_{50}$ values. * Cu-DPPZ-Phen (3) injected in micro-suspension.

\begin{tabular}{|c|c|c|c|c|}
\hline \multirow[t]{2}{*}{ Compounds } & \multicolumn{4}{|l|}{$\mathrm{LD}_{50}(\mu \mathrm{g}) \pm \mathrm{S} . \mathrm{D}$} \\
\hline & $4 \mathrm{~h}$ & $24 \mathrm{~h}$ & $48 \mathrm{~h}$ & $72 \mathrm{~h}$ \\
\hline Cu-Phen (1) & $12.62 \pm 0.008$ & $8.94 \pm 0.006$ & $8.94 \pm 0.006$ & $8.56 \pm 0.75$ \\
\hline Cu-DPQ-Phen (2) & $21.53 \pm 0.007$ & $11.47 \pm 0.006$ & $10.69 \pm 0.005$ & $9.88 \pm 0.017$ \\
\hline Cu-DPPZ-Phen (3)* & $26.07 \pm 0.312$ & $25.05 \pm 0.312$ & $25.05 \pm 0.312$ & $16.81 \pm 0.236$ \\
\hline
\end{tabular}


Table 3

Statistically Significant Differentially Abundant (SSDA) proteins present in $\mathrm{Cu}$ Phen (1), Cu-DPQ-Phen (2) and Cu-DPPZ-Phen (3) in comparison to the solvent control. Relative fold changes are given for each complex exposure in comparison to the solvent control.

\begin{tabular}{|c|c|c|c|}
\hline \multirow[t]{2}{*}{ Protein annotation } & \multicolumn{3}{|c|}{ Relative expression to solvent control } \\
\hline & $\begin{array}{l}\text { Cu-Phen } \\
\text { (1) }\end{array}$ & $\begin{array}{l}\text { Cu-DPQ- } \\
\text { Phen (2) }\end{array}$ & $\begin{array}{l}\text { Cu-DPPZ- } \\
\text { Phen (3) }\end{array}$ \\
\hline $\begin{array}{l}\text { Aldehyde dehydrogenase mitochondrial- } \\
\text { like }\end{array}$ & 2.19 & 7.16 & 8.05 \\
\hline Selenium-binding 1 & 2.02 & 6.62 & 7.8 \\
\hline Lambda-crystallin homolog & 4.89 & 6.76 & 7.55 \\
\hline Tubulin beta chain & 4.64 & 6.37 & 7.41 \\
\hline D-arabinitol dehydrogenase 1-like & 5.24 & 5.8 & 6.85 \\
\hline Elongation factor 1 -alpha & 6.19 & 5.57 & 6.63 \\
\hline $\begin{array}{l}\text { 15-hydroxyprostaglandin } \\
\text { dehydrogenase }[\mathrm{NAD}(+)] \text {-like }\end{array}$ & 2.96 & 5.05 & 6.49 \\
\hline Cytoplasmic A3a & 1.28 & 5.74 & 6.4 \\
\hline$N$-acetylneuraminate lyase-like & 5.17 & 5.69 & 6.38 \\
\hline Serine cytosolic isoform $\mathrm{X} 1$ & 0.63 & 5.48 & 6.36 \\
\hline Multifunctional ADE2 & 5.13 & 5.13 & 6.19 \\
\hline Cytosolic malate partial & 2.81 & 4.97 & 6.16 \\
\hline D-3-phosphoglycerate dehydrogenase & 3.05 & 5.27 & 6.04 \\
\hline Glutathione $S$-transferase-like & 5.18 & 4.65 & 5.99 \\
\hline Tubulin alpha chain & 4.68 & 4.6 & 5.9 \\
\hline Triosephosphate isomerase & 4.92 & 4.96 & 5.87 \\
\hline Glutamine synthetase 2 cytoplasmic-like & 3.61 & 5 & 5.41 \\
\hline Probable enoyl- mitochondrial & 1.09 & 4.61 & 5.31 \\
\hline Glutathione $S$-transferase 1-1-like & 2.78 & 4.6 & 5.22 \\
\hline Glyceraldehyde-3-phosphate partial & 3.14 & 4.6 & 5.04 \\
\hline $\begin{array}{l}\text { Fructose-bisphosphate aldolase isoform } \\
\quad \text { X1 }\end{array}$ & 4.59 & 4.14 & 4.94 \\
\hline $\begin{array}{l}\text { Superoxide dismutase }[\mathrm{Mn}] \\
\text { mitochondrial }\end{array}$ & -1.52 & 3.53 & 4.7 \\
\hline $\begin{array}{l}\text { Trans-1,2-dihydrobenzene-1,2-diol } \\
\text { dehydrogenase-like }\end{array}$ & 4.69 & 4.17 & 4.7 \\
\hline Bifunctional purine biosynthesis PURH & 1.75 & 3.7 & 4.56 \\
\hline Aminopeptidase & 1.39 & 3.34 & 4.39 \\
\hline Heat shock 90 & 3.39 & 3.36 & 4.33 \\
\hline Enolase & 3.49 & 2.95 & 4.32 \\
\hline L-threonine ammonia-lyase-like & 4.08 & 3.3 & 4.27 \\
\hline Arginine partial & 4.02 & 2.04 & 4.24 \\
\hline Aliphatic nitrilase & 3.61 & 3.19 & 4.19 \\
\hline Dihydropteridine reductase & 6.24 & 3.4 & 4.13 \\
\hline Peptidyl-prolyl cis-trans isomerase & 3.03 & 3.12 & 4.13 \\
\hline Cholinesterase 1-like & 6.1 & 3.64 & 4.02 \\
\hline Purine nucleoside phosphorylase & 3.49 & 1.96 & 3.97 \\
\hline Cellular retinoic acid binding & 5.01 & 3.06 & 3.77 \\
\hline Argininosuccinate synthase & 1.28 & 2.66 & 3.74 \\
\hline Uncharacterized protein Dmoj_GI19595 & 2.25 & 1.91 & 3.65 \\
\hline Immune-related Hdd1 & 4.43 & 3.58 & 3.57 \\
\hline Ejaculatory bulb-specific 3-like & 2.05 & 3.68 & 3.52 \\
\hline Fibrous sheath CABYR-binding & 5.16 & 2.89 & 3.46 \\
\hline Leukotriene A-4 hydrolase isoform X2 & 2.13 & 3.26 & 3.13 \\
\hline $\begin{array}{l}\text { PREDICTED: uncharacterized protein } \\
\text { LOC106129042 }\end{array}$ & 3.89 & 3.23 & 3.13 \\
\hline Ecdysteroid-regulated $16 \mathrm{kDa}$-like & 2.54 & 3.23 & 2.64 \\
\hline $\begin{array}{l}\text { Isopentenyl-diphosphate Delta- } \\
\text { isomerase } 1\end{array}$ & -1.01 & 2.13 & 2.55 \\
\hline Heat shock & 1.98 & 2.2 & 2.4 \\
\hline Proliferation-associated 2G4 & 2.61 & 1.98 & 2.35 \\
\hline Seroin-like isoform $\mathrm{X} 2$ & -2.06 & 1.37 & 2.28 \\
\hline Actin & 1.63 & 4.22 & 1.99 \\
\hline Nucleoside diphosphate kinase & -0.66 & 0.79 & 1.83 \\
\hline Chitin deacetylase 1 & 6.88 & 1.52 & 1.55 \\
\hline Contig19736_1_exp_NA & 1.43 & -1.62 & -1.82 \\
\hline Homeobox 2-like isoform X4 & 3.15 & -1.33 & -2.15 \\
\hline Probable salivary secreted peptide & 2.9 & -1.72 & -2.8 \\
\hline Gloverin-like & 0.92 & -2.5 & -2.96 \\
\hline Peptidoglycan recognition & 2.03 & -4.02 & -3.28 \\
\hline Glutathione $S$-transferase 1 -like & 5.11 & - & 4.67 \\
\hline Profilin & 3.18 & - & 3.64 \\
\hline Aminoacrylate peracid reductase & -0.69 & - & 3.35 \\
\hline Cytosolic non-specific dipeptidase & 2.23 & - & 3.1 \\
\hline Circadian clock-controlled -like & 3.01 & - & 2.7 \\
\hline 4-Coumarate-ligase 1-like & 1.16 & - & 2.62 \\
\hline
\end{tabular}

Table 3 (continued)

\begin{tabular}{|c|c|c|c|}
\hline \multirow[t]{2}{*}{ Protein annotation } & \multicolumn{3}{|c|}{ Relative expression to solvent control } \\
\hline & $\begin{array}{l}\text { Cu-Phen } \\
\text { (1) }\end{array}$ & $\begin{array}{l}\text { Cu-DPQ- } \\
\text { Phen (2) }\end{array}$ & $\begin{array}{l}\text { Cu-DPPZ- } \\
\text { Phen (3) }\end{array}$ \\
\hline $\begin{array}{l}\text { Multiple inositol polyphosphate } \\
\text { phosphatase 1-like }\end{array}$ & 1.14 & - & 1.86 \\
\hline Isocitrate partial & 2.7 & - & 1.48 \\
\hline Esterase FE4-like & 5.06 & - & -1.18 \\
\hline Thioredoxin & - & 3.87 & 4.81 \\
\hline Rab GDP dissociation inhibitor alpha & - & 3.15 & 4.55 \\
\hline $\begin{array}{l}\text { Probable phosphoserine } \\
\text { aminotransferase }\end{array}$ & - & 4.23 & 4.46 \\
\hline Small heat shock & - & 3.46 & 3.97 \\
\hline Takeout-like & - & 2.33 & 3.97 \\
\hline High mobility group D & - & 2.27 & 3.74 \\
\hline $\begin{array}{l}\text { Staphylococcal nuclease domain- } \\
\text { containing } 1\end{array}$ & - & 2.13 & 3.16 \\
\hline Glutathione $S$-transferase omega 1 & - & 2.07 & 2.92 \\
\hline Fumarylacetoacetase & - & 1.57 & 2.35 \\
\hline Hydroxypyruvate isomerase & - & 1.1 & 1.76 \\
\hline Apolipophorins isoform X2* & - & -4.15 & -0.72 \\
\hline Chitinase ENO3 (imaginal disc growth)* & - & -0.72 & -1.5 \\
\hline Translationally controlled tumor & 5.64 & - & - \\
\hline Cysteine ase inhibitor precursor & 2.71 & - & - \\
\hline Gustatory receptor candidate 59 & 2.5 & - & - \\
\hline Chemosensory & 2.48 & - & - \\
\hline Serpin-2 & - & 2.00 & - \\
\hline Muscle-specific 20 & - & - & 5.73 \\
\hline Peroxiredoxin- mitochondrial & - & - & 4.96 \\
\hline Tropomyosin-1 isoform X1 & - & - & 4.22 \\
\hline Troponin $\mathrm{T}$ & - & - & 4.18 \\
\hline Annexin B9 isoform X4 & - & - & 4.15 \\
\hline Troponin I & - & - & 3.97 \\
\hline Asteroid & - & - & 3.62 \\
\hline Antichymotrypsin-2-like isoform X2 & - & - & 3.56 \\
\hline $\begin{array}{l}\text { Ubiquitin carboxyl-terminal hydrolase } \\
\text { isozyme L3 }\end{array}$ & - & - & 3.14 \\
\hline S-Adenosyl-L-homocysteine partial & - & - & 3.08 \\
\hline $\begin{array}{l}\text { C-1-tetrahydrofolate cytoplasmic } \\
\text { isoform X2 }\end{array}$ & - & - & 3.03 \\
\hline Troponin C & - & - & 2.88 \\
\hline Phosphoglycerate mutase 1 & - & - & 2.82 \\
\hline Probable transaldolase & - & - & 2.78 \\
\hline ATPase inhibitor & - & - & 2.28 \\
\hline Acyl-binding homolog & - & - & 1.99 \\
\hline Proactivator polypeptide & - & - & 1.74 \\
\hline Phosphotriesterase-related -like & - & - & 1.71 \\
\hline L-threonine 3- mitochondrial & - & - & 1.66 \\
\hline Prostaglandin reductase 1 & - & - & 1.57 \\
\hline Vanin 2 isoform $\mathrm{X} 1$ & - & - & -1.79 \\
\hline $\begin{array}{l}\text { Chymotrypsin-like elastase family } \\
\text { member } 2 \mathrm{~A}\end{array}$ & - & - & -2.3 \\
\hline Serine protease 42 -like & - & - & -2.41 \\
\hline
\end{tabular}

- denotes level of expression that was either absent or not detected. Fold changes of ${ }^{<} 1.5$ were included when expression in other test exposures was $\geq 1.5$ fold change. *Denotes protein also expressed in 2D PAGE analysis with a similar profile, see Supplementary Table III. Numerical difference between the detected proteins between the two proteomics methods was due to the greater sensitivity of LFQ proteomics method.

function (Fig. 4(B)) with categorisations being performed at level 4 ontology. The biological process analysis (Fig. 4(A)) does not show any major changes in larvae inoculated with the different complexes. Protein groups such as precursor metabolites, organonitrogen and cellular nitrogen associated proteins were more prominent in terms of observed proteins. An overall increase was observed in the number of proteins recorded after exposure to Cu-DPQ-Phen (2) and Cu-DPPZ-Phen (3) with the number of proteins increasing as the ligated phenazine $\pi$ backbone was extended. However, the number of proteins associated with each GO process proportionally increased in comparison to $\mathrm{Cu}$ Phen (1). Interestingly, proteins associated with sulphur compounds and cellular aldehyde processes were only present after exposure to $\mathrm{Cu}$ - 


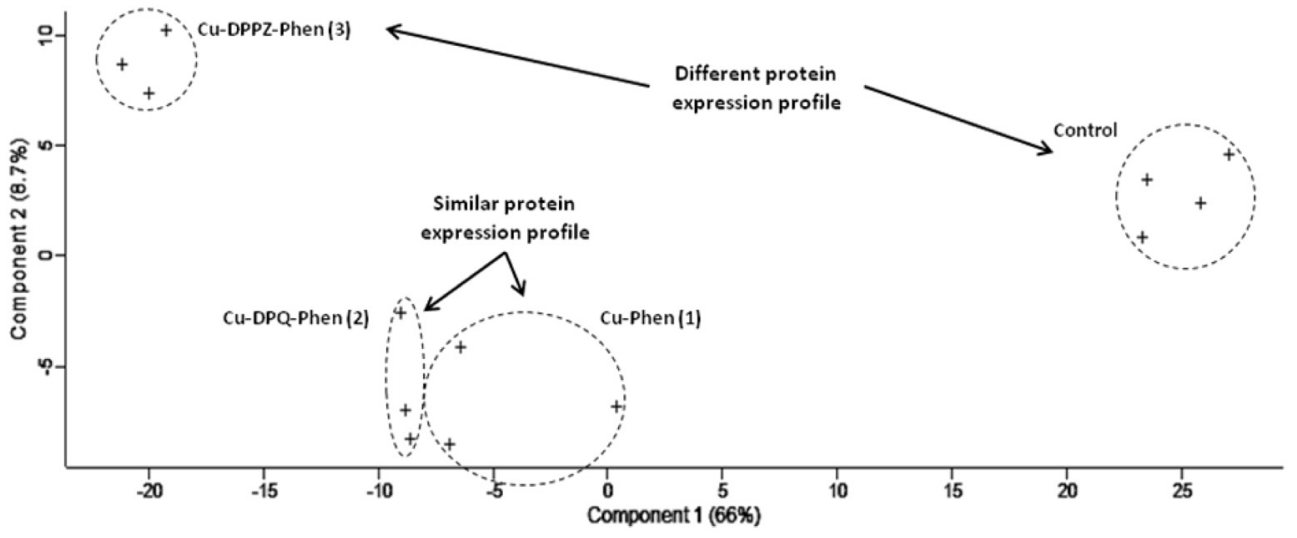

Fig. 3. Principle component analysis (PCA) of haemolymph proteomic profiles of larvae inoculated with Cu-Phen (1), Cu-DPQ-Phen (2) and Cu-DPPZ-Phen (3) versus the solvent control. PCA of four replicates for the solvent control and three replicates for each of the test exposures. Enclosures define the different experimental conditions. Component 1 on the $\mathrm{x}$-axis represents the largest difference in terms of protein expression profile with Component 2 on the $y$ axis representing the next largest.

A

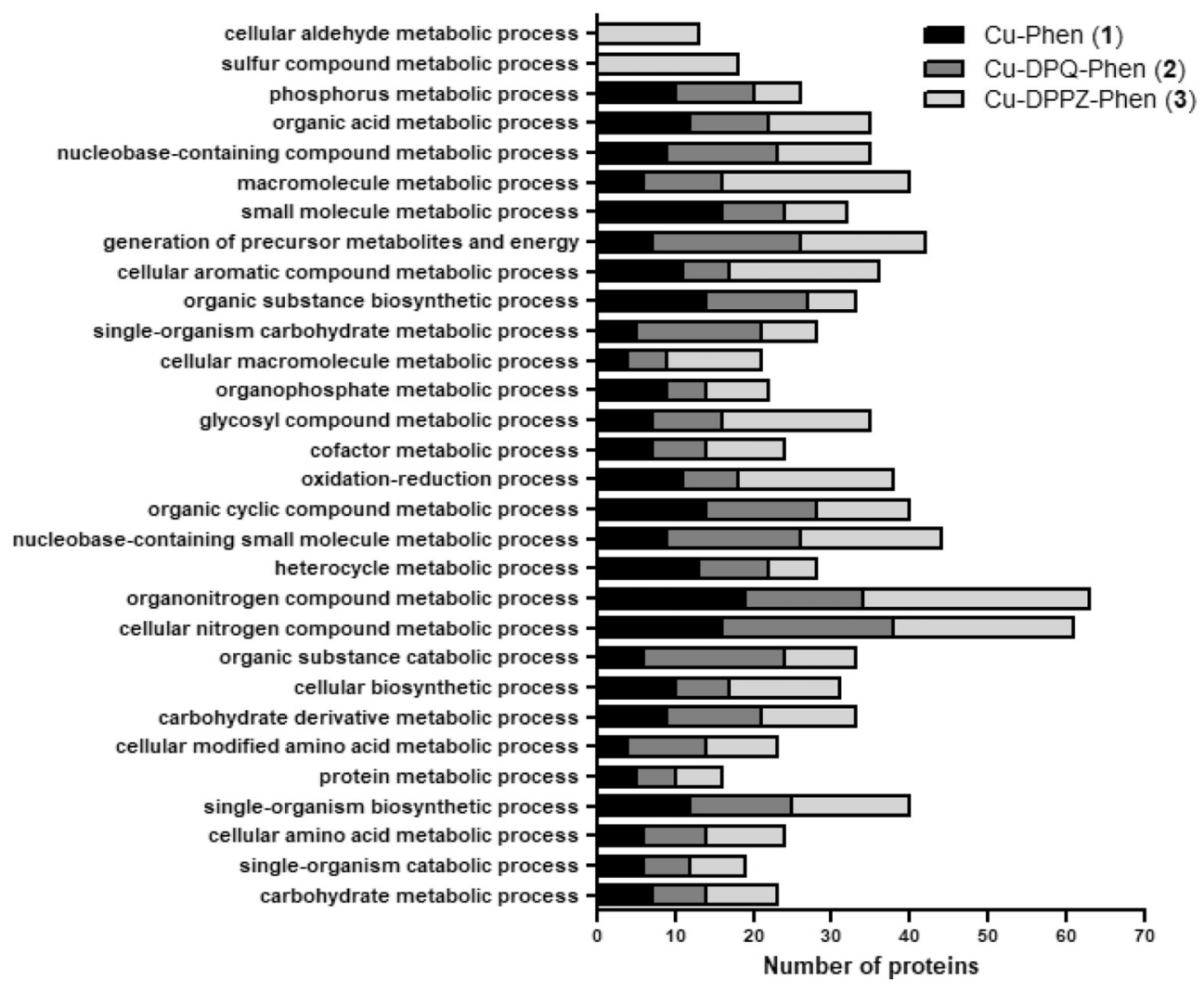

B

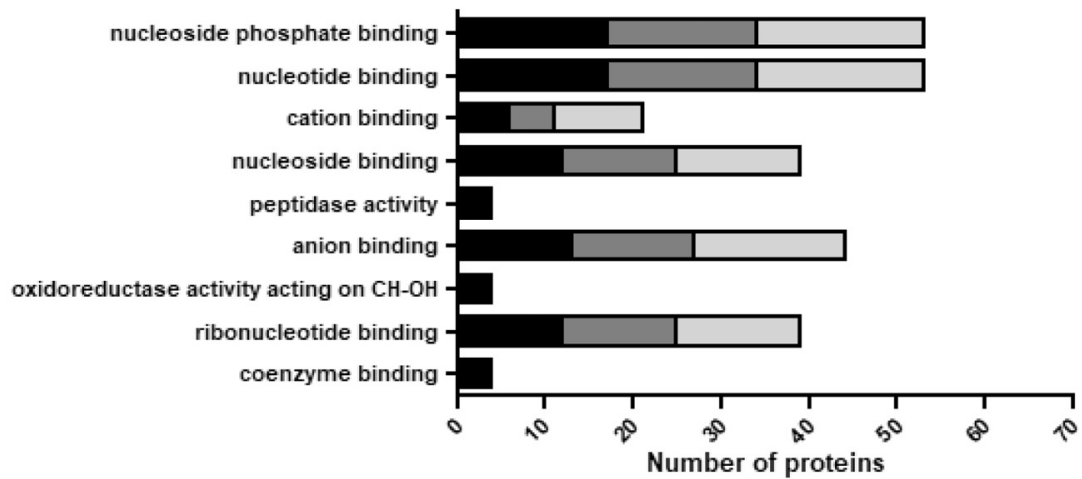

Fig. 4. Bar chart showing the different number of proteins present in a test exposure that is associated with selected biological processes (A) and molecular functions (B). Comparative bar chart represents level 4 ontology. 
DPPZ-Phen (3). Analysis of molecular functions (Fig. 4(B)) also showed a similar trend of increasing number of proteins involved in the functionally categorised processes as the $\mathrm{Cu}(\mathrm{II})$ series progressed from $\mathrm{Cu}$ Phen $>$ Cu-DPQ-Phen $>$ Cu-DPPZ-Phen. Proteins associated with coenzyme binding, oxidoreductases acting on $\mathrm{CH}-\mathrm{OH}$ and peptidase activity was only associated with exposure of Cu-Phen (1), while all other protein groups were co expressed by all three test complexes. Glutathione $S$-transferase (GST) highlighted in the KEGG analysis (Fig. 5), exhibited an increased relative abundance following exposure to Cu-Phen (1), Cu-DPQ-Phen (2) and Cu-DPPZ-Phen (3) in comparison to the control. KEGG glycolysis/gluconeogenesis analysis (Fig. 6) of all three complex exposures showed an upregulation of several proteins: fructose bisphosphate, triose phosphate isomerase, glyceraldehydes-3phosphate dehydrogenase and phosphopyruvate hydratase (enolase). KEGG analysis of purine metabolism (Fig. 7) showed increased relative abundance of 6 proteins after exposure to all test complexes: phosphoribosylaminoimidazolesuccinocarboxamide (SAICAR) synthase, phosphoribosylaminoimidazolecarboxamide (AICAR) formyltransferase, IMP cyclohydrolase, nucleoside-diphosphate kinase, nucleoside-triphosphate phosphatise and purine-nucleoside phosphorylase.

\section{Discussion}

The aim of this study was to assess the response of G. mellonella larvae to novel copper phenanthroline-phenazine complexes as a means to determine their biological mode of action and therefore developmental potential. Larval mortality decreased as the ligated phenazine ligand in the $\left[\mathrm{Cu}(\mathrm{phen})\left(\mathrm{N}, \mathrm{N}^{\prime}\right)\right]^{2+}$ model was extended (Cu-Phen (1) > Cu-DPQ-Phen (2) > Cu-DPPZ-Phen (3)). The mortality assay demonstrates that the complex series had superior toxicity at all timepoints to cisplatin with the exception of Cu-DPPZ-Phen (3) which, in comparison to Cu-Phen (1) and Cu-DPQ-Phen (2) was relatively nontoxic. Previous studies have confirmed the enhanced toxicity of copper complexes in comparison to platinum agents in G. mellonella larvae [42].

Immune priming often plays a large role in the larval response to foreign bodies, either chemical or pathological and alterations in the larval haemocyte density is one of the earliest markers of the invertebrate immune response [60]. Both controls and complex series induced a non-significant increase in the haemocyte response after complex exposure, which indicates that the novel $\mathrm{Cu}(\mathrm{II})$ complex series does not elicit a generalised cellular immune response. The non-stimulation of a non-specific immune response was also shown with the

METABOLISM OF XENOBIOTICS BY CYTOCHROME P450
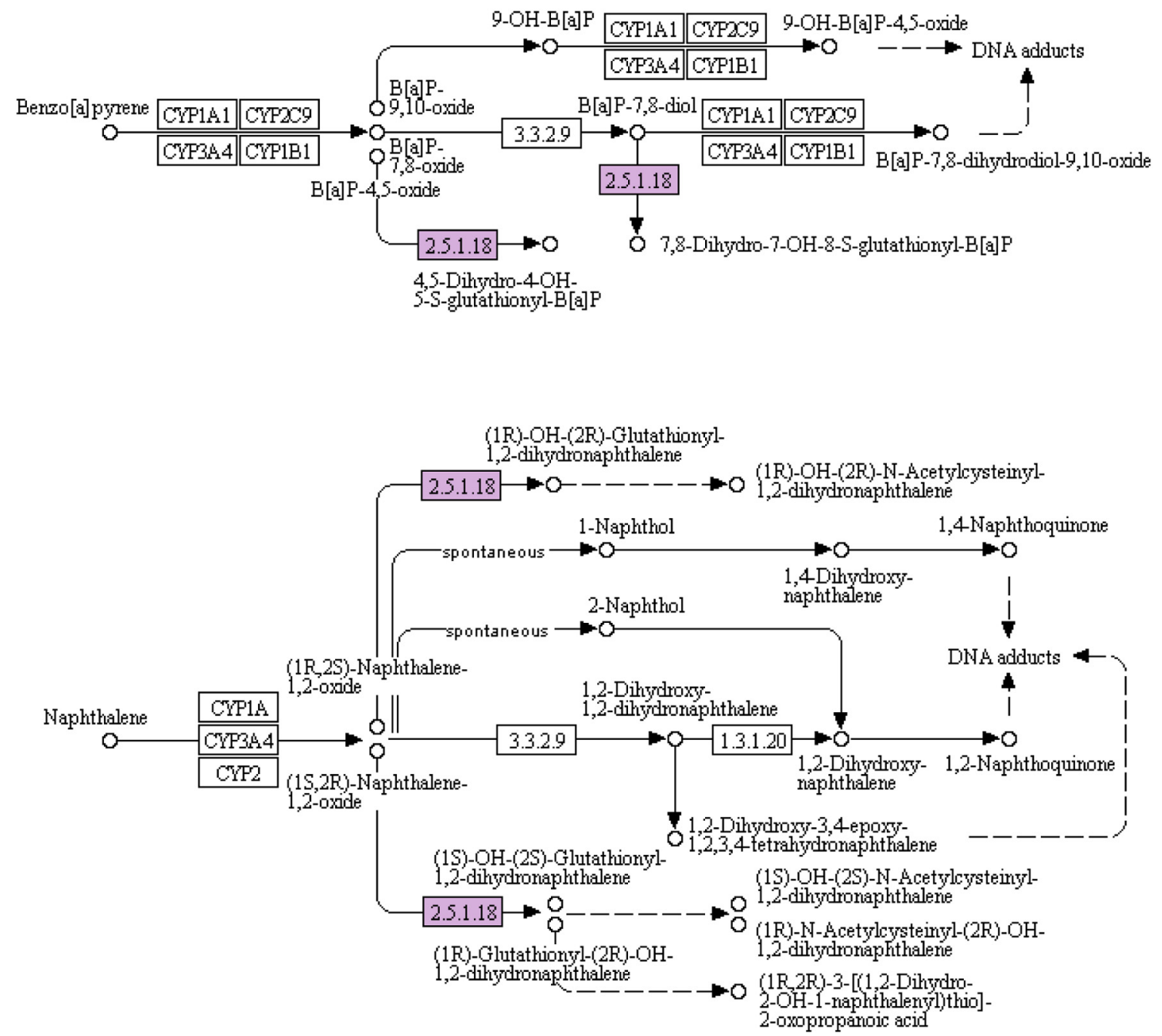

Fig. 5. KEGG analysis of the metabolism of selected xenobiotics by cytochrome P450. Glutathione $S$-transferase (2.5.1.18) (pink) is shown to be significantly upregulated in all test exposures. 


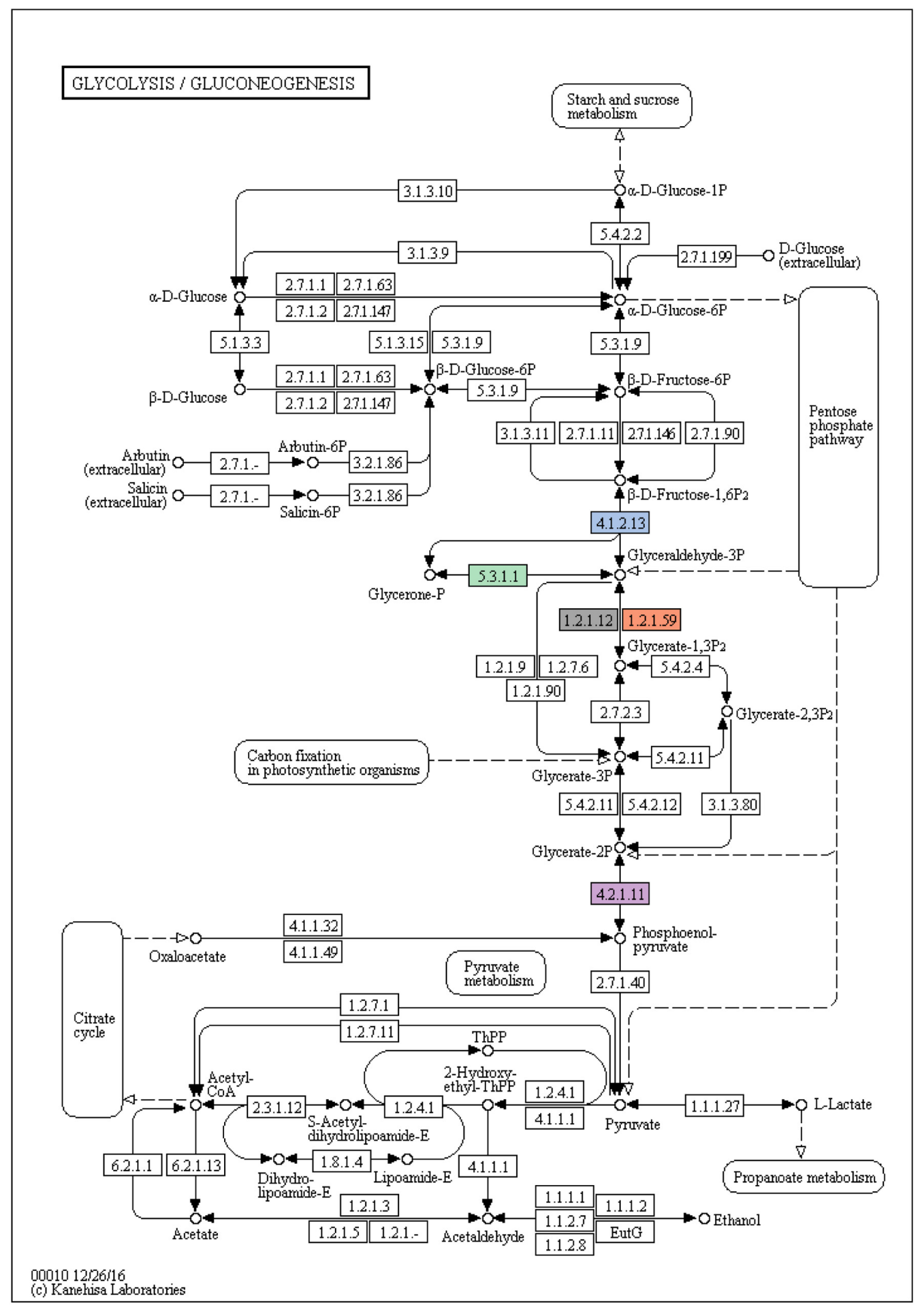

Fig. 6. KEGG analysis of significantly upregulated proteins in glycolysis/gluconeogenesis (highlighted: blue, green, grey, orange and pink) between all test exposures. Cu-DPQ-Phen (2) shows no upregulation of 4.2.1.11 (phosphopyruvate hydratase) (pink). 


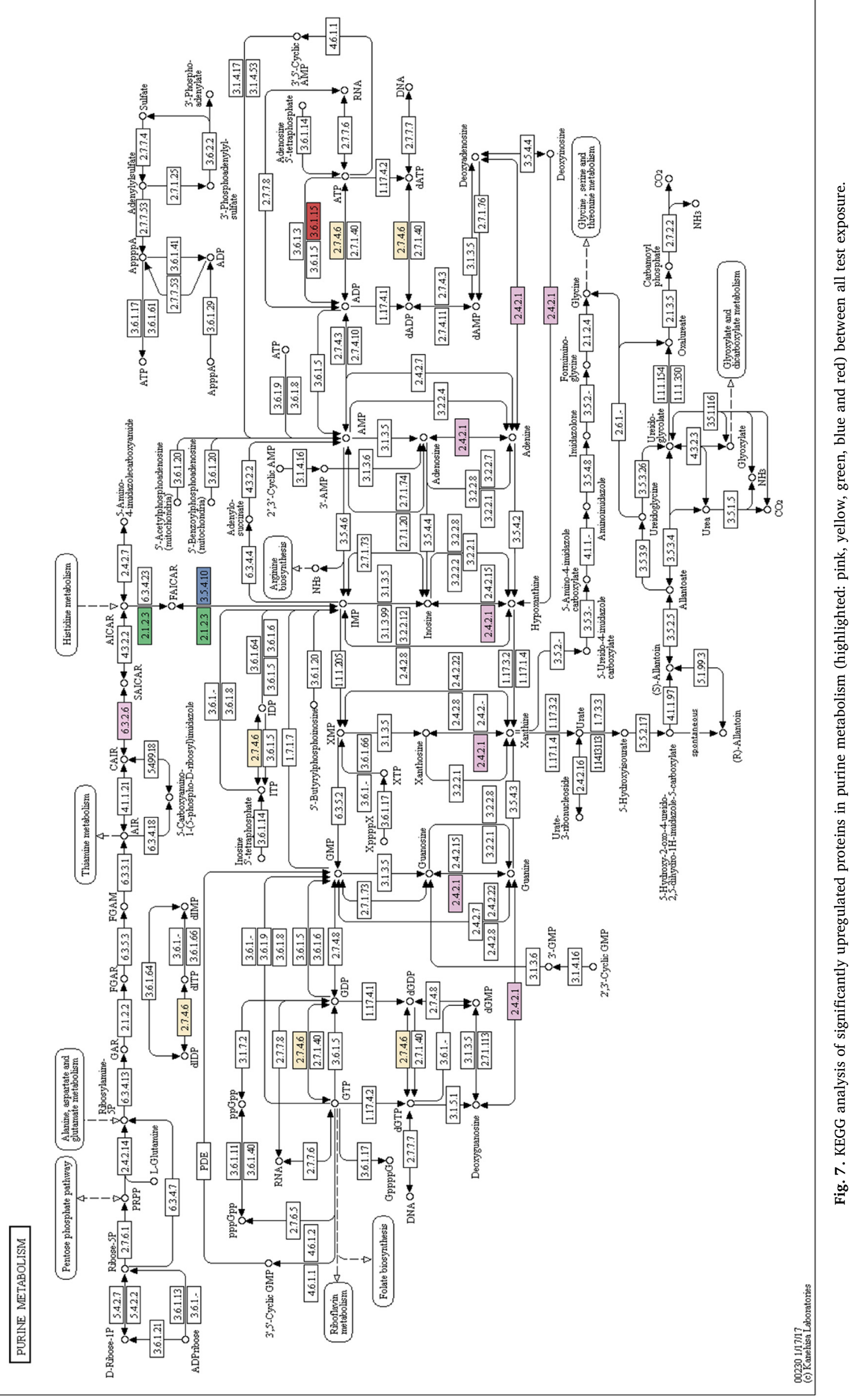


evaluation of the antimicrobial effects of 1,3-dibenzyl-4,5-diphenylimidazol-2-ylidene silver(I) acetate (SBC3) in G. mellonella post infection with Staphylococcus aureus and Candida albicans [44]. In contrast, other studies have shown a priming of the larval immune response with biologically derived echinocandines producing a resistance to subsequent infection [53]. The priming of the immune response has been previously observed through amplification of immune related genes [41, 54, 61]. This study in contrast shows significant decreases in IMPI and transferrin gene expression after exposure to the metallo-agents compared to the solvent control. Transferrin is typically increased following infection and based on functional homology with mammalian systems, sequesters biologically active iron from circulation to prevent it from being used as a microbial growth factor. IMPI was first identified in G. mellonella and is responsible for breaking down metal based proteases released by microbial pathogens [62]. Significantly, across the complex series there is no increase in either of these antimicrobial factors, indicating that at a cellular and messenger Ribonucleic Acid (mRNA) level, the $\mathrm{Cu}(\mathrm{II})$ complexes are not eliciting a larval immune response in a similar fashion to carbene silver(I) acetate (SBC3) exposure [44]. In contrast, the larval exposure to caspofungin induces an immune priming reaction [53].

In this study, LFQ proteomics produced a high-resolution analysis of the larval response to the complex series with the possibility of gaining an insight into the potential response in the mammalian system. Twodimensional poly acrylamide gel electrophoresis (2D-PAGE) provides a lower resolution confirmation of several proteins detected in the LFQ proteomics. Using 2D-PAGE proteomics the downregulation of three proteins was confirmed in addition to 4 other detections of lower abundance proteins (Supplementary Table V-VI). Both 2D-PAGE and LFQ proteomics supports the finding of decreased immune response found in the immune related gene expression and the non-significant increase in the larval haemocyte response. 2D-PAGE analysis showed that imaginal disc growth factor and apolipophorin was downregulated in larvae treated with either Cu-DPQ-Phen (2) or Cu-DPPZ-Phen (3). Additionally, transferrin, juvenile like binding hormone and $27 \mathrm{kDa}$ hemolymph protein was downregulated after exposure of larvae to $\mathrm{Cu}$ DPPZ-Phen (3). All larvae were exposed to the $24 \mathrm{~h} \mathrm{LD}_{50}$ value of the 3 complexes but have a different number of proteins significantly altered in abundance.

GST is a family of phase II detoxification enzymes that catalyses the conjugation of glutathione to a wide variety of endogenous and exogenous electrophilic compounds by making the exogenous molecule more hydrophilic, which aids in its elimination [63, 64]. Studies have shown GST abundance to be elevated during oxidative stress in the mammalian system [65]. Evidence has also linked the GST isozymes to anti-cancer drug resistance [66]. The action of copper $N$-(2-hydroxy acetophenone) glycinate has shown promise in overcoming doxorubicin generated GST and Multi Drug Resistance (MDR) [67]. KEGG analysis of the metabolism of xenobiotics by cytochrome P450 (Fig. 5) highlighted the involvement of GST in detoxification of benzo-[a]-pyrene and napthalene both of which contain polycyclic aromatic rings which are present in the phenazine ligand in Cu-DPQ-Phen (2) and Cu-DPPZPhen (3). The upregulation of GST is also involved in the detoxification of cyclophosphamide and ifosfamide which are key therapeutic alkylating agents. Cu-Phen (1), Cu-DPQ-Phen (2) and Cu-DPPZ-Phen (3) have previously been shown to have nuclease cleaving ability [32], and potentially interact with DNA through intercalation properties at the minor groove as seen with the ruthenium complex $\Lambda$ - $[\mathrm{Ru}$ (phen) $\left.)_{2} \mathrm{dppz}\right]^{2+}[68]$.

Cu-DPQ-Phen (2) and Cu-DPPZ-Phen (3) have previously been shown to generate excellent Superoxide Dismutase (SOD) mimetic activity with a progressive Fenton reaction matching the cadence of the chemical nuclease capacity against pUC19 DNA [32]. Mitochondrial aldehyde dehydrogenase and mitochondrial superoxide dismutase have been shown to be closely associated with oxidative stress [69, 70]. The upregulation of activity of these proteins in both the Cu-DPQ-Phen (2) and Cu-DPPZ-Phen (3) treated larvae may be associated with increased oxidative stress. Aldehyde dehydrogenase in mammalian cells has been associated with tolerance to increased organic nitrates [71], which are known to produce oxidative stress. The upregulation of both aldehyde dehydrogenase and superoxide dismutase in the Cu-DPQ-Phen (2) and Cu-DPPZ-Phen (3) treated larvae rather than just the upregulation of aldehyde dehydrogenase in the Cu-Phen (1) may indicate that oxidative stress plays a stronger mechanistic role in the secondary phenazine ligands despite the lower $\mathrm{LD}_{50}$ value. Isocitrate dehydrogenase is only upregulated in Cu-Phen (1) exposure while malate dehydrogenase is only upregulated in Cu-DPQ-Phen (2) and Cu-DPPZ-Phen (3) treated larvae. These dehydrogenases are closely linked to the Tricarboxylic Acid (TCA) cycle and have an effect on Nicotinamide Adenine Dinucleotide $+/ \mathrm{H}(\mathrm{NAD}+/ \mathrm{NADH})$ ratio, which has been the subject of renewed interest due to its capacity to alter/ameliorate the effects on aging and other complex disease phenotypes [72]. An additional dehydrogenase present at increased levels of abundance in all exposures is 15-hydroxylprostaglandin dehydrogenase $[\mathrm{NAD}(+)]$ which has been shown to suppress eicosanoids such as prostaglandins and liposin, previously demonstrated to have anticancer properties [73].

KEGG analysis of glycolysis/gluconeogenesis (Fig. 6) indicated upregulation of fructose bisphosphate, triose phosphate isomerase, glyceraldehydes-3-phosphate dehydrogenase and phosphopyruvate hydratase (enolase) after exposure to all complexes. Previous studies have shown enolase to become up regulated in response to cellular stress [74]. Based on the study conducted by Molphy et al. [32], Cu(II) phenanthroline-phenazine complexes showed chemical nuclease activity in pUC19 plasmid DNA. Chemical nuclease action on larval DNA may have contributed to cellular stress and related alterations in carbohydrate metabolism. Glyceraldehyde-3-phosphate dehydrogenase was also highlighted and is involved in the conversion of glyceraldehydes-3phosphate to D-glycerate. The non-enzymatic elimination of phosphate groups from glyceraldehyde-3-phosphate can lead to the production of the cytotoxic methylglyoxal which is known to be a progenitor of advanced glycation end-products [75].

Purine metabolism from KEGG analysis (Fig. 7) indicated increased abundance of regulatory enzymes SAICAR, AICAR and other purine support enzymes. Changes in purine metabolism as a result of cellular stress states have promoted increased interest recently as a potential therapeutic target for new drug development [76]. Among some of the new studies is evidence for the formation of a dynamic multi-enzyme complex (purinosome) proximal to the mitochondria and microtubules [77]. The formation of this multimeric protein complex has been associated with the depletion of purines and the upregulation of heat shock 90 protein (HSP90) which aids in higher order protein structure [76]. Based on the KEGG analysis, HSP90 was observed at higher levels of abundance in larvae treated with all test complexes highlighting the potential involvement of the newly described purinosome in the mechanistic response to nuclease active drugs due to accelerated DNA breakdown from the cleavage activity of the metal complexes.

The GO analysis demonstrated marked elevation in the following protein groups: cellular nitrogen compound metabolic process, organonitrogen compound metabolic process, heterocyclic metabolic process, organic cyclic compound metabolic process, organic substance biosynthetic process and small molecule metabolic process associated proteins. The increased abundance of proteins associated with the complex series and in particular, Cu-DPQ-Phen (2) and Cu-DPPZ-Phen (3) are accompanied by a broad upregulation in detoxification and degradation pathways. The increased abundance of nitrogen containing, heterocyclic and small molecule related metabolism most likely reflects the cellular detoxification response to the complexes which peaks upon administration with Cu-DPQ-Phen (2) and Cu-DPPZ-Phen (3). The GO analysis of molecular function at level 4 ontology showed an elevated group of proteins indicative of DNA binding by all the test complexes; nucleotide binding and nucleoside phosphate binding. The upregulated activity of these groups of proteins may reflect an 
increased association with DNA damage and potential repair complexes. Radical hydroxyl attack is believed to be an effect of these complexes owing to their previously established Fenton chemistry [32].

\section{Conclusion}

This investigation showed that the extension of the phenazine $\pi$ backbone within the complex scaffold resulted in a decrease in both mortality and immune response in the larval model with the trend following Cu-Phen $<$ Cu-DPQ-Phen $<$ Cu-DPPZ-Phen. Similarly to previous studies, enhanced toxicity is observed with increased nuclease capacity, however in contrast enhanced DNA binding and thermal melting stability governed by the extended phenazine $\pi$-framework results in a decrease in mortality here [16, 78].

The label free quantitation (LFQ) mass spectrometry method produced a high-resolution assessment of the proteomic changes occurring in the larvae in response to test complexes allowing for gene ontology (GO) analysis of both biological and molecular functions to be performed. The results indicated a prominent metabolic and detoxification response which may provide an opportunity to develop drug targeting to this region but also to utilise the larval model to evaluate future therapeutic and targeting improvements.

\section{Acknowledgments}

The authors would like to thank the Dublin Institute of Technology (DIT) for providing the Fiosraigh funding (funding call 2013) for this research project. Q-Exactive mass spectrometer was funded under the SFI Research Infrastructure Call 2012; Grant Number: 12/RI/2346 (3). ZM acknowledges support by Irish Research Council (IRC) grant GOIPG/2013/826.

\section{Financial disclosures}

Authors have no financial conflicts to disclose.

\section{Conflicts of interest}

Authors have none to declare.

\section{Appendix A. Supplementary data}

Supplementary data to this article can be found online at https:// doi.org/10.1016/j.jinorgbio.2018.05.020.

\section{References}

[1] H. Song, J.T. Kaiser, J.K. Barton, Nat. Chem. 4 (2012) 615-620.

[2] H. Niyazi, J.P. Hall, K. O'Sullivan, G. Winter, T. Sorensen, J.M. Kelly, C.J. Cardin, Nat. Chem. 4 (2012) 621-628.

[3] J.P. Hall, D. Cook, S.R. Morte, P. McIntyre, K. Buchner, H. Beer, D.J. Cardin, J.A. Brazier, G. Winter, J.M. Kelly, C.J. Cardin, J. Am. Chem. Soc. 135 (2013) 12652-12659.

[4] A.J. McConnell, H. Song, J.K. Barton, Inorg. Chem. 52 (2013) 10131-10136.

[5] C.J. Cardin, J.M. Kelly, S.J. Quinn, Chem. Sci. 8 (2017) 4705-4723.

[6] J. Chen, J. Stubbe, Nat. Rev. Cancer 5 (2005) 102-112.

[7] J. Malina, M.J. Hannon, V. Brabec, Chem. Eur. J. 21 (2015) 11189-11195.

[8] S.J. Berners-Price, A. Filipovska, Metallomics 3 (2011) 863-873.

[9] T. Zou, C.T. Lum, C.-N. Lok, J.-J. Zhang, C.-M. Che, Chem. Soc. Rev. 44 (2015) 8786-8801.

[10] Z. Du, R.E.F. de Paiva, K. Nelson, N.P. Farrell, Angew. Chem. Int. Ed. 56 (2017) $4464-4467$

[11] A. Prisecaru, M. Devereux, N. Barron, M. McCann, J. Colleran, A. Casey, V. McKee, A. Kellett, Chem. Commun. 48 (2012) 6906-6908.

[12] A. Kellett, O. Howe, M. O'Connor, M. McCann, B.S. Creaven, S. McClean, A. FoltynArfa Kia, A. Casey, M. Devereux, Free Radic. Biol. Med. 53 (2012) 564-576.

[13] M. McCann, J. McGinley, K. Ni, M. O'Connor, K. Kavanagh, V. McKee, J. Colleran, M. Devereux, N. Gathergood, N. Barron, A. Prisecaru, A. Kellett, Chem. Commun. 49 (2013) 2341-2343.

[14] C. Santini, M. Pellei, V. Gandin, M. Porchia, F. Tisato, C. Marzano, Chem. Rev. 114 (2014) 815-862
[15] R. Larragy, J. Fitzgerald, A. Prisecaru, V. McKee, P. Leonard, A. Kellett, Chem. Commun. 51 (2015) 12908-12911.

[16] C. Slator, N. Barron, O. Howe, A. Kellett, ACS Chem. Biol. 11 (2016) 159-171.

[17] C. Marzano, M. Pellei, F. Tisato, C. Santini, Anti Cancer Agents Med. Chem. 9 (2009) 185-211.

[18] S. Tardito, L. Marchio, Curr. Med. Chem. 16 (2009) 1325-1348.

[19] F. Tisato, C. Marzano, M. Porchia, M. Pellei, C. Santini, Med. Res. Rev., 30, 708-749.

[20] N.P. Farrell, Chem. Soc. Rev. 44 (2015) 8773-8785.

[21] A. Gupta, S. Lutsenko, Future Med. Chem. 1 (2009) 1125-1142.

[22] R. Galindo-Murillo, J.C. García-Ramos, L. Ruiz-Azuara, T.E. Cheatham, F. CortésGuzmán, Nucleic Acids Res. 43 (2015) 5364-5376.

[23] C. Mejia, L. Ruiz-Azuara, Pathol. Oncol. Res. 14 (2008) 467-472.

[24] C. Trejo-Solís, G. Palencia, S. Zuñiga, A. Rodríguez-Ropon, L. Osorio-Rico, S. Torres Luvia, I. Gracia-Mora, L. Marquez-Rosado, A. Sánchez, M.E. Moreno-García, A. Cruz, M.E. Bravo-Gómez, L. Ruiz-Ramírez, S. Rodríquez-Enriquez, J. Sotelo, Neoplasia 7 (2005) 563-574.

[25] F. Carvallo-Chaigneau, C. Trejo-Solís, C. Gómez-Ruiz, E. Rodríguez-Aguilera, L. Macías-Rosales, E. Cortés-Barberena, C. Cedillo-Peláez, I. Gracia-Mora, L. RuizAzuara, V. Madrid-Marina, F. Constantino-Casas, Biometals 21 (2008) 17-28.

[26] M.E. Bravo-Gómez, C. Campero-Peredo, D. García-Conde, M.J. Mosqueira-Santillán, J. Serment-Guerrero, L. Ruiz-Azuara, Polyhedron 102 (2015) 530-538.

[27] D.S. Sigman, D.R. Graham, V. D'Aurora, A.M. Stern, J. Biol. Chem. 254 (1979) 12269-12272.

[28] D.S. Sigman, Acc. Chem. Res. 19 (1986) 180-186.

[29] D.S. Sigman, T.W. Bruice, A. Mazumder, C.L. Sutton, Acc. Chem. Res. 26 (1993) 98-104.

[30] C. Slator, Z. Molphy, V. McKee, C. Long, T. Brown, A. Kellett, Nucleic Acids Res. (2018), http://dx.doi.org/10.1093/nar/gky105.

[31] A. Prisecaru, V. McKee, O. Howe, G. Rochford, M. McCann, J. Colleran, M. Pour, N. Barron, N. Gathergood, A. Kellett, J. Med. Chem. 56 (2013) 8599-8615.

[32] Z. Molphy, A. Prisecaru, C. Slator, N. Barron, M. McCann, J. Colleran, D. Chandran, N. Gathergood, A. Kellett, Inorg. Chem. 53 (2014) 5392-5404.

[33] G. Cotter, S. Doyle, K. Kavanagh, FEMS Immunol. Med. Microbiol. 27 (2000) 163-169.

[34] K. Kavanagh, E.P. Reeves, FEMS Microbiol. Rev. 28 (2004) 101-112.

[35] M. Kemp, R.C. Massey, Drug Discov, Today 4 (2007) 105-110.

[36] K. Kavanagh, J.P. Fallon, Fungal Biol. Rev, 24 (2010) 79-83.

[37] N. Browne, M. Heelan, K. Kavanagh, Virulence 4 (2013) 597-603.

[38] J. Renwick, K. Kavanagh, Kevin Kavanagh (Ed.), New Insights in Medical Mycology, 1 Springer, Netherlands, 2007, pp. 45-67 Ch. 2

[39] S.M. Cook, J.D. McArthur, Virulence 4 (2013) 350-353.

[40] D. Bergin, E.P. Reeves, J. Renwick, B. Frans, K. Kavanagh, F.B. Wientjes, Infect. Immun. 73 (2005) 4161-4170.

[41] D. Bergin, L. Murphy, J. Keenan, M. Clynes, K. Kavanagh, Microbes Infect. 8 (2006) 2105-2112.

[42] M. McCann, A.L.S. Santos, B.a. da Silva, M.T.V. Romanos, A.S. Pyrrho, M. Devereux, K. Kavanagh, I. Fichtner, A. Kellett, Toxicol. Res. 1 (2012) 47.

[43] M. McCann, R. Curran, M. Ben-Shoshan, V. McKee, M. Devereux, K. Kavanagh, A. Kellett, Polyhedron 56 (2013) 180-188.

[44] N. Browne, F. Hackenberg, W. Streciwilk, M. Tacke, K. Kavanagh, Biometals 27 (2014) 745-752.

[45] A. Kellett, M. O'Connor, M. McCann, O. Howe, A. Casey, P. McCarron, K. Kavanagh, M. McNamara, S. Kennedy, D.D. May, P.S. Skell, D. O'Shea, M. Devereux, Med. Chem. Commun 2 (2011) 569-676.

[46] Z. Molphy, C. Slator, C. Chatgilialoglu, A. Kellett, Front. Chem. 3 (2015) 1-9.

[47] A. D'Alessandro, S. Rinalducci, L. Zolla, J. Proteome 74 (2011) 2575-2595.

[48] Y. Wang, J.F. Chiu, Metal-Based Drugs (2008), http://dx.doi.org/10.1155/2008/ 716329.

[49] G. Cotter, S. Doyle, K. Kavanagh, FEMS Immunol. Med. Microbiol. 27 (2000) $163-169$.

[50] N. Browne, C. Surlis, K. Kavanagh, J. Insect Physiol. 63 (2014) 21-26.

[51] L. Vertyporokh, I. Wojda, Acta Biochim. Pol. 64 (2016) 6.

[52] T. Yoshiga, T. Georgieva, B.C. Dunkov, N. Harizanova, K. Ralchev, J.H. Law, Eur. J. Biochem. 260 (1999) 414-420.

[53] J. Kelly, K. Kavanagh, J. Med. Microbiol. 60 (2011) 189-196.

[54] I. Wojda, T. Jakubowicz, J. Insect Physiol. 53 (2007) 1134-1144.

[55] R. Maguire, M. Kunc, P. Hyrsl, K. Kavanagh, Comp. Biochem. Physiol., Part C: Toxicol. Pharmacol. 195 (2017) 44-51.

[56] A. Shevchenko, H. Tomas, J. Havlis, J.V. Olsen, M. Mann, Nat. Protoc. 1 (2006) 2856-2860.

[57] J. Cox, N. Neuhaurser, A. Michalskit, R.A. Scheltema, J.V. Olsen, M. Mann, J. Proteome Res. 10 (2011) 1794-1805.

[58] H. Vogel, B. Altincicek, G. Glöckner and A. Vilcinskas, BMC Genomics, 2011, 12, DOI: $1471-2164 / 12 / 308$

[59] K.J. Livak, T.D. Schmittgen, Methods 25 (2001) 402-408.

[60] N. Browne, An Analysis of the Cellular and Humoral Immune Responses of Galleria Mellonella Larvae, Maynooth University, 2014.

[61] A.N. Volkoff, J. Rocher, E. D'Alençon, M. Bouton, I. Landais, E. Quesada-Moraga, A. Vey, P. Fournier, K. Mita, G. Devauchelle, Gene 319 (2003) 43-53.

[62] M. Wedde, C. Weise, P. Kopacek, P. Franke, A. Vilcinskas, Eur. J. Biochem. 255 (1998) 535-543.

[63] D. Bartolini, J. Commodi, M. Piroddi, L. Incipini, L. Sancineto, C. Santi, F. Galli, Free Radic. Biol. Med. 88 (2015) 466-480.

[64] A.A. Enayati, H. Ranson, J. Hemingway, Insect Mol. Biol. 14 (2005) 3-8.

[65] P. G. Board, D. Menon, Biochim. Biophys, Acta 1830 (2013) 3267-3288. 
[66] D.M. Townsend, K.D. Tew, Oncogene 22 (2003) 7369-7375.

[67] S. Majumder, P. Dutta, A. Mookerjee, S.K. Choudhuri, Chem. Biol. Interact. 159 (2006) 90-103.

[68] H. Niyazi, J. Hall, K. O'Sullivan, G. Winter, T. Sorensen, J. Kelly, C. Cardin, Nat. Chem. 4 (2012) 621-628.

[69] A. Daiber, Mol. Pharmacol. 66 (2004) 1372-1382.

[70] J. McCord, I. Fridovich, Free Radic. Biol. Med. 5 (1988) 363-369.

[71] Z. Chen, J. Zhang, J.S. Stamler, Proc. Natl. Acad. Sci. U. S. A. 99 (2002) 8306-8311.

[72] Y. Yang, A.A. Sauve, Biochim. Biophys. Acta 1864 (2016) 1787-1800.

[73] S. Tuncer, S. Banerjee, World J. Gastroenterol. 21 (2015) 11748-11766.
[74] H. Ji, J. Wang, J. Guo, Y. Li, S. Lian, W. Guo, H. Yang, F. Kong, L. Zhen, L. Guo, Y. Liu, Anim. Nutr. Health 2 (2016) 12-17.

[75] I. Allaman, M. Bélanger, P.J. Magistretti, Front. Neurosci. 9 (2015) 1-12.

[76] I. Chitrakar, D.M. Kim-Holzapfel, W. Zhou, J.B. French, J. Struct. Biol. 197 (2017) 354-364.

[77] A.M. Pedley, S.J. Benkovic, Trends Biochem. Sci. 42 (2017) 141-154.

[78] M. Devereux, M. McCann, D. O'Shea, M. O'Connor, E. Kiely, V. McKee, D. Naughton, A. Fisher, A. Kellett, M. Walsh, D. Egan, C. Deegan, Bioinorg. Chem. Appl. (2005), http://dx.doi.org/10.1155/BCA/2006/80283. 